\title{
Hyponatremia in Patients with Community Acquired Pneumonia
}

\author{
Lochan Karki, ${ }^{1}$ Bhawesh Thapa, ${ }^{1}$ Manoj Kumar Sah' ${ }^{1}$ \\ 'Department of Internal Medicine, NAMS, Bir Hospital, Kathmandu, Nepal.
}

Introduction: Community acquired pneumonia is one the frequent cause of hospital admissions. Whereas, hyponatremia is a common electrolyte abnormality in hospitalized patients and has been shown to be associated with considerable morbidity and mortality. We aim to studyt the association of hyponatremia with community acquired pneumonia in terms of morbidity and mortality.

Methods: A prospective observational hospital based study was conducted in a hospital for a year. All patients with a diagnosis of community acquired pneumonia and admitted in medicine ward, were included. Patients with diarrhea, known Chronic Kidney Disease, Heart Failure, Cirrhosis of Liver, Malignancy, taking diuretics, chemical pneumonitis, interstitial pneumonias and other debilitating disease were excluded.

Results: Among the 72 cases of CAP, 61\% were females and 39\% were males. The mean age of patients was 51.3 years, $22(30.55 \%)$ patients had severe CAP. A total of 7 cases expired with an overall mortality of $13.7 \%$. The mortality risk increased with increasing CURB-65 score; CURB-65 score $0,0 \%$; CURB-65 score 1, 0\%; CURB-65 score 2, 0\%; CURB-65 score 3, 10\%; CURB-65 score 4 , $33 \%$; CURB-65 score 5, 100\%. i.e higher the CURB-65 score, higher the death rate of CAP patients $(\mathrm{p}<0.05)$. Hyponatremia was a common occurrence at hospital admission with an incidence of $36.11 \%$. Hyponatremia at hospital admission was also associated with a longer length of hospital stay in cured CAP patients. The mean length of hospital stay was 4.3 days.

Conclusions: High CURB-65 scores and lower values of serum sodium at admission in patients of CAP are associated with adverse outcomes both in terms of mortality and longer length of hospital stay. CURB-65 score should be incorporated into assessment of CAP and sodium of the patients during admission.

Keywords: CURB-65 score; hyponatremia; mortality.

\section{INTRODUCTION}

Community acquired pneumonia (CAP) is a common disorder with an incidence of about $20-30 \%$ in developing countries and $3-4 \%$ in developed countries ${ }^{1}$ and potentially serious illness associated with considerable morbidity and mortality particularly in elderly patients with significant comorbidities. ${ }^{2}$ It is estimated that Nepal, India, Bangladesh and Indonesia account for $40 \%$ of global acute respiratory infections; $90 \%$ mortality is due to pneumonia mostly bacterial in origin. $^{3}$

Several risk stratification algorithms, such as CURB (confusion, urea, respiratory rate, blood pressure), CURB-65 and Pneumonia Severity Index(PSI), have been developed to help identify patients at high risk of CAP-related complications, and to make appropriate

Correspondence: Dr. Lochan Karki, Department of Internal Medicine, NAMS, Bir Hospital, Kathmandu, Nepal. Email: drlochankarki@ gmail.com, Phone: +977-9851056689. 
site-of-care decisions. ${ }^{4}$ Moreover, hyponatremia occurs in $15-30 \%$ of hospitalized patients. ${ }^{5}$ Hyponatremia has clearly been shown to be a common electrolyte abnormality in pneumonia. Therefore, the aim of the study was to determine the relation of hyponatremia in patients admitted with community acquired pneumonia.

\section{METHODS}

A prospective observational hospital based study was conducted in Department of Internal Medicine, Bir Hospital from May 2015 to April 2016. Ethical approval was taken. After calculating sample size, patients with a diagnosis of community acquired pneumonia and admitted in medicine ward, were included. Patients with diarrhea, known Chronic Kidney Disease, Heart Failure, Cirrhosis of Liver, Malignancy, taking diuretics, oral rehydration salts, diagnosed as nosocomial pneumonia, with Tuberculosis and HIV infection and with chemical pneumonitis, interstitial pneumonias were excluded.

All data was collected using a structured proforma covering the relevant details. Admitted patients with a diagnosis of CAP fulfilling the inclusion criteria from emergency room or from medical OPD were enrolled. On admission, a detailed history was taken from the patient and/or caregiver and a thorough physical examination was done. Relevant laboratory investigations complete blood count $(C B C)$, renal function tests (serum urea, creatinine, sodium, potassium), serum glucose, liver function tests, Urine routine examination, HIV serology were done. Chest radiograph was ordered and reported by the radiologist as far as possible. CURB-65 score was calculated and the patient was categorized into mild and severe pneumonia according to the CURB-65 score. Informed consent was taken from the caregivers or relatives or patients. Data on arterial blood gas analysis was only available for those with clinical signs of respiratory distress judged by primary care emergency physicians.

Blood sample was collected aseptically by a single prick from a peripheral vein without tying any tourniquet as soon as they are admitted and serum sodium was specifically noted. Determination of serum sodium was done using ion selective electrode method.

The patients were attended daily during hospital admission to know the status of the patient. Follow up was at 30 days if in hospital or called for follow up or contact by telephone.Data were entered using Statistical Package for Social Studies (SPSS version 20) software.

\section{RESULTS}

A total 72 patients of community acquired pneumonia (CAP) admitted the hospital during the study period of 1 year. Out of 72 patients of CAP, 28 (39\%) patients were males $44(61 \%)$ CAP patients were females. The number of female patients was found to be nearly double.

Total 21 patients were found to have others comorbidities as well. Chronic Obstructive Pulmonary Disease was found in $9(12.5 \%)$ patients, Diabetes mellitus (DM) in $4.2 \%$, hypertension in $11.11 \%$ and DM plus hypertension in 1 patient; whereas in 51 patients, CAP was observed without co-morbidities (Figure 1).

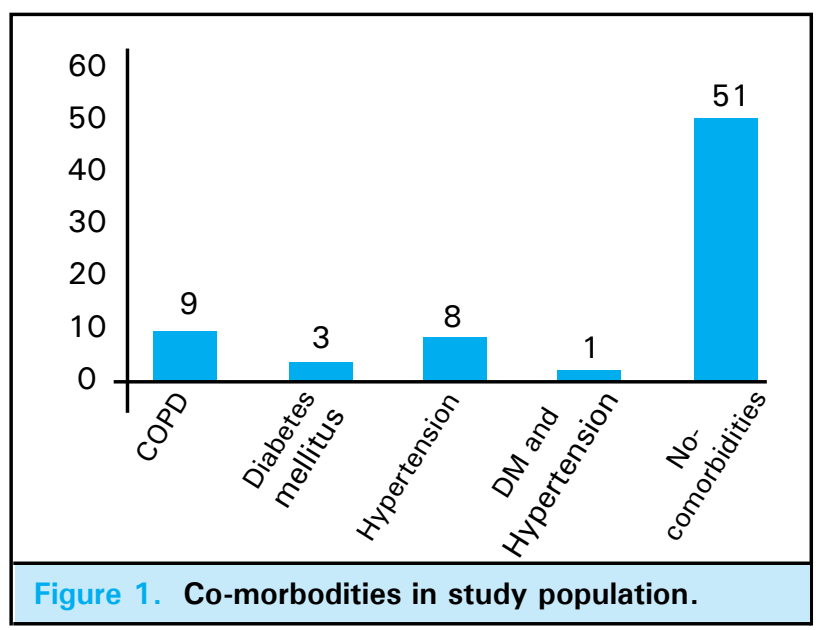

Total 7 patients expired during this study period had mean serum $\mathrm{Na}+$ concentration $128.14 \mathrm{mmol} / \mathrm{l}$ with standard deviation 3.5, with minimum value of 123 $\mathrm{mmol} / \mathrm{l}$ and maximum value of $133 \mathrm{mmol} / \mathrm{l}$. Similarly, the mean $\mathrm{K}+$ concentration was found to be $3.94 \mathrm{mmol} / \mathrm{l}$ with std. deviation 0.53 . The maximum value of $K+$ was found to be $5 \mathrm{mmol} / \mathrm{l}$ and minimum concentration was $3 \mathrm{mmol} / \mathrm{l}$. In same group of expired patients, the mean value of creatinine was found to be $1.43 \mathrm{mg} / \mathrm{dl}$, std. deviation 0.34 , minimum value 1.2 and maximum value 1.6 (Figure 2).

Among the 72 CAP patients, 65 patients were cured. In these cured patients, the mean value of serum $\mathrm{Na}+$ concentration was found to be $137.82 \mathrm{mmol} / \mathrm{l}$, minimum value $120 \mathrm{mmol} / \mathrm{l}$ and maximum value $149 \mathrm{mmol} / \mathrm{l}$ with standard deviation of 5.6. Similarly, the maximum value of $\mathrm{K}+$ was found to be $5 \mathrm{mmol} / \mathrm{l}$, minimum value 3 $\mathrm{mmol} / \mathrm{l}$ and mean value 4.03 with standard deviation 0.52 . 
Karki et al. Clinical Evaluation of Fused/Ankylosed Hip with Severe Flexion Deformity after Conversion to Total Hip Arthroplasty

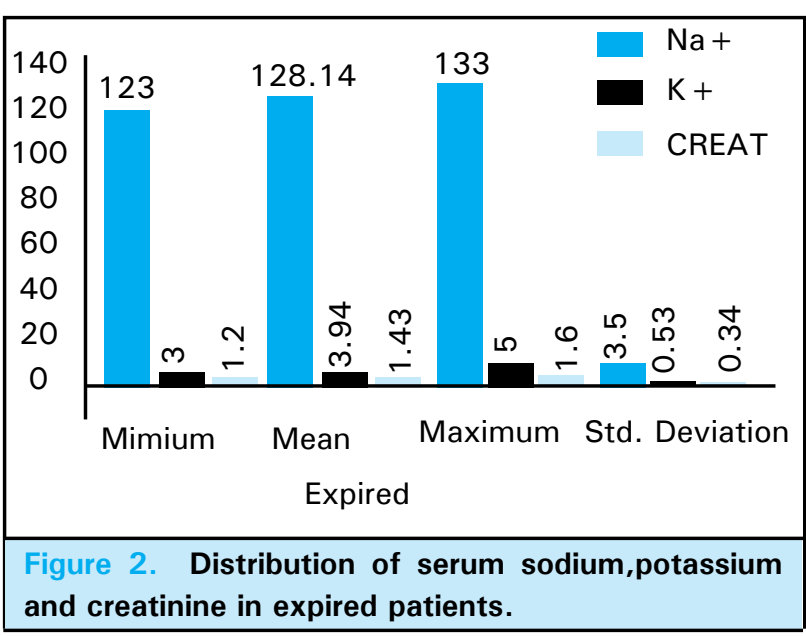

All Highest number of patients were grouped in CURB65 score 2 i.e. $22(30.56 \%)$ patients followed by 19 (26.39\%) patients (Table 1 ). Similarly, same patients were categorized in to five groups on the basis of serum sodium level. Among the 72 patients with CAP, $26(36.11 \%$ ) patients had hyponatremia (serum sodium

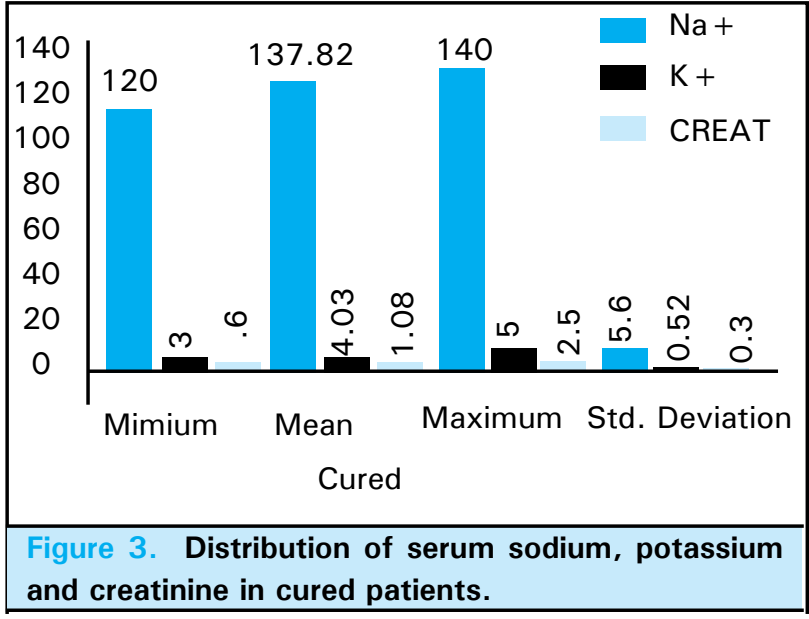

less than $135 \mathrm{mmol} / \mathrm{l})$ among whom $17(23.6 \%)$ patients were found to have mild hyponatremia whereas $7(23.61 \%)$ patients were found to have moderate hyponatremia and $2(2.77 \%)$ patients were found to have severe hyponatremia (Table 1 ).

\begin{tabular}{|c|c|c|c|c|c|c|}
\hline $\begin{array}{l}\text { CURB-65 } \\
\text { Score }\end{array}$ & $\begin{array}{l}\text { Mild } \\
\text { Hyponatremia } \\
\text { (plasma sodium } \\
-130-134 \\
\mathrm{mmol} / \mathrm{l} \text { ) }\end{array}$ & $\begin{array}{l}\text { Moderate } \\
\text { Hyponatremia } \\
\text { (plasma sodium } \\
-125-129 \mathrm{mmol} / \mathrm{l} \text { ) }\end{array}$ & $\begin{array}{l}\text { Severe } \\
\text { Hyponatremia } \\
\text { (plasma sodium } \\
<125 \mathrm{mmol} / \mathrm{l} \text { ) }\end{array}$ & $\begin{array}{l}\text { Normal } \\
\text { serum } \\
\text { sodium } \\
(135-145 \\
\mathrm{mmol} / \mathrm{l})\end{array}$ & $\begin{array}{l}\text { Hypernatremia (serum sodium } \\
>145 \mathrm{mmol} / \mathrm{l} \text { ) Hypernatremia } \\
\text { (serum sodium }>145 \mathrm{mmol} / \mathrm{l} \text { ) } \\
\text { Hypernatremia (serum sodium } \\
>145 \mathrm{mmol} / \mathrm{l} \text { ) }\end{array}$ & Total \\
\hline 0 & 0 & 0 & 0 & 8 & 1 & 9 \\
\hline 1 & 2 & 0 & 0 & 17 & 0 & 19 \\
\hline 2 & 5 & 0 & 0 & 15 & 2 & 22 \\
\hline 3 & 5 & 3 & 1 & 0 & 1 & 10 \\
\hline 4 & 5 & 2 & 0 & 2 & 0 & 9 \\
\hline 5 & 0 & 2 & 1 & 0 & 0 & 3 \\
\hline Total & 17 & 7 & 2 & 42 & 4 & 72 \\
\hline
\end{tabular}

In this study, higher the CURB-65 score, higher the death rate of CAP patient (Table 2 ).

\begin{tabular}{|cccc|}
\hline \multicolumn{4}{|c|}{$\begin{array}{l}\text { Table 2. Distribution of cured and expired patients } \\
\text { according to CURB-65 score. }\end{array}$} \\
\hline CURB-65 Score & Cured & Expired & Total \\
0 & 9 & 0 & 9 \\
1 & 19 & 0 & 19 \\
2 & 22 & 0 & 22 \\
3 & 9 & 1 & 10 \\
4 & 6 & 3 & 9 \\
5 & 0 & 3 & 3 \\
Total & 65 & 7 & 72 \\
\hline
\end{tabular}

The death rate was found to be high in moderate and severe hyponatremia in comparison to mild hyponatremia and without hyponatremia CAP cases (Table 3).

\begin{tabular}{|lccc|}
\hline \multicolumn{4}{|l|}{ Table 3. Distribution of cured and expired patients } \\
according to serum sodium level. & Cured & Death & Total \\
\hline $\begin{array}{l}\text { Hyponatremia } \\
\text { Hyponatremia (plasma } \\
\text { sodium 130-134 mmol/I) }\end{array}$ & 15 & 2 & 17 \\
$\begin{array}{l}\text { Moderate Hyponatremia } \\
\text { (plasma sodium 125-129 } \\
\text { mmol/l) }\end{array}$ & 3 & 4 & 7 \\
$\begin{array}{l}\text { Severe Hyponatremia } \\
\text { (plasma sodium <125 } \\
\text { mmol/I) }\end{array}$ & 1 & 1 & 2 \\
$\begin{array}{l}\text { No Hyponatremia(plasma } \\
\text { sodium }>135 \text { mmol/l) }\end{array}$ & 46 & 0 & 46 \\
Total & 65 & 7 & 72 \\
\hline
\end{tabular}

In case of expired CAP patients, the maximum hospital 
stay day was found to be 9 days and minimum days of hospital stay was 3 days with mean days 5.57 days. The hospital stays of expired patients was shorter than improved patients (Figure 4).

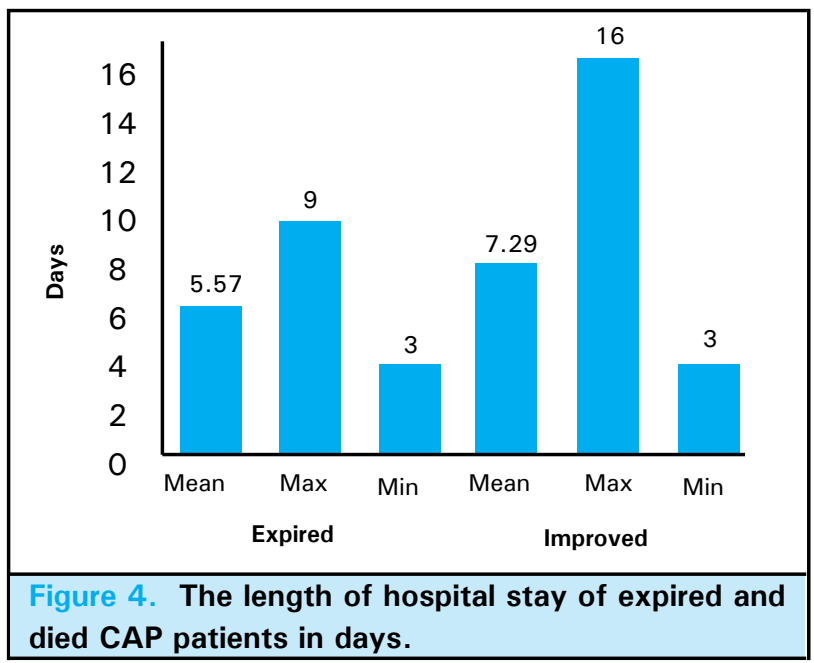

\section{DISCUSSION}

CAP is a common illness, with a majority of patients treated outside hospital, yet the greatest burden of the cost of care comes from inpatient management. The decision regarding the most important site of care, including whether admission to hospital is warranted, is the first and single most important decision in the overall management of CAP. ${ }^{6}$ The best accepted tools to discriminate patients with CAP into high and low risk are the CURB-65 score and the Pneumonia Severity Index.

British thoracic Society recommends CURB-65 score to evaluate severity of CAP. Patients with low score (0-2) are likely to be suitable for home treatment, as the expected mortality is low. Higher scores (3-5) are associated with increasing mortality and admission to hospital is recommended. Patients should be assessed for Intensive Care Unit admission if the score is 4 or $5 .^{7}$

The gender distribution showed that there were more female patients $61 \%$ with CAP compared to male patients $39 \%$. The ratio of Female:Male patients was 1.56:1. Study conducted by Shah BA, Sing G, Naik $\mathrm{MA}$, et al. in CAP also showed more number of Female than male patients $(\mathrm{F}: \mathrm{M}=1.38: 1){ }^{8}$

The mean age of all patients was 51.3 years in our study. The mean age of males in this study was $56.961 \pm$ SD 13.57) and that of females was $79.47( \pm S D$ 17.60). A study done by $A M$ Neill et al. in CAP patients found the mean age to be 58 years (range $18-97$ years) and of them, $55 \%$ were men. ${ }^{9}$ admission was common in our study which showed the incidence of hyponatremia in approximately onethird $(36.11 \%)$ i.e 26 of 72 patients with Community acquired pneumonia having serum sodium levels less than $135 \mathrm{mmol} / \mathrm{l}$. This is similar to study done by Nair and coworkers in CAP patients who found the prevalence of hyponatremia, defined as $[\mathrm{Na}+]<135$ $\mathrm{mmol} / \mathrm{L}$ in the first hospital-obtained sample, to be $28 \% .^{10}$ In contrast, hypernatremia was uncommon at presentation with only $4(5.55 \%)$ patients were having serum sodium $>145 \mathrm{mmol} / \mathrm{l}$ at admission.

The mortality rate of CAP patients increased as the severity of hyponatremia also increased. Total 4 out of $7(57.14 \%)$ patients with moderate hyponatremia and $50 \%$ of patients with severe hyponatremia expired. Among the patients with mild hyponatremia, only 2 out of $15(13.33 \%)$ expired.The mean serum sodium level in cured patients was $137.82 \mathrm{mmol} / \mathrm{l}$ compared to $128.14 \mathrm{mmol} / \mathrm{l}$ in patients who expired.The death rate of CAP patients were found to be increasing as the increase in level of severity of hyponatremia and was found to be statistically significant at the level of $95 \%$ $\mathrm{Cl}$ i.e. P-value $<0.05$

The cured patients with CAP, the average length of hospital stay (LOHS)was 10.1 days in patients with hyponatremia compared to 5.79 days in patients without hyponatremia (increase in LOHS of 4.3 days). Previous studies also have shown that hyponatremia frequently accompanies hospitalization for pneumonia and is associated with adverse outcomes.Study conducted by Nair $\mathrm{V}$ et al. and Marya D Zilbergerg also concluded admission sodium was an independent predictor of mortality and morbidity outcomes in terms of hospital stay, ICU admission and the need for mechanical ventilation in patients with pneumonia.

Our study showed significant difference $(p<0.05)$ in mortality in patients with high platelet count $>$ $400,000 / \mathrm{mm}^{3}$. Study done by Mirsaedi M, Peyrani $P$ et al. reported high platelet count at the time of hospitalization in patients with CAP to be strongly associated ( $p=0.0009$ ) with 30 day mortality. ${ }^{11}$ Another study conducted by Prina et al. showed significant relation between both low and high platelet counts and increased mortality. ${ }^{12}$

The limitation of the study includes, there were limited numbers of patients under study, randomization was not done, time duration was limited, various associated comorbid conditions were not taken into account during the study which could have contributed to the adverse outcomes, sputum Gram stain staining and culture sensitivity was not done also microbiological diagnosis of

Hyponatremia among CAP patients at hospital 
CAP could not be ascertained.

\section{CONCLUSIONS}

Hyponatremia was frequently associated in patients with CAP and was associated with an adverse clinical outcome including death and longer length of hospital stay. The severity of hyponatremia increases with the severity of community acquired pneumonia and CURB-65 score is a good predictor for the severity of pneumonia. Hence, CURB-65 score should be incorporated into assessment of CAP patients during admission. Similarly, serum sodium should be strictly checked at admission and steps needs to be carried out immediately for better outcome of the patients.

\section{REFERENCES}

1. Garibaldi RA. Epidemiology of community-acquired respiratory tract infections in adults: incidence, etiology, and impact. The American journal of medicine. 1985 Jun 28;78(6):32-7.

2. Mandell LA, Wunderink RG, Anzueto A, Bartlett JG, Campbell GD, Dean NC, et al. Infectious Diseases Society of America/American Thoracic Society consensus guidelines on the management of community-acquired pneumonia in adults. Clinical infectious diseases. 2007 Mar 1;44(Supplement 2):S27-72

3. Shah BA, Ahmed W, Dhobi GN, Shah NN, Khursheed SQ, Haq I. Validity of pneumonia severity index and CURB-65 severity scoring systems in community acquired pneumonia in an Indian setting. The Indian journal of chest diseases \& allied sciences. 2010 Jan;52(1):9.

4. Fine MJ, Auble TE, Yealy DM, Hanusa BH, Weissfeld LA, Singer DE, Coley CM, Marrie TJ, Kapoor WN. A prediction rule to identify low-risk patients with community-acquired pneumonia. New England journal of medicine. 1997 Jan 23;336(4):243-50.

5. Ellison DH, Berl T. Clinical practice. The syndrome ofinappropriate antidiuresis. New England Journal of Medicine. 2007;356 2064-2072.
6. Ewig S, Torres A, Woodhead M. Assessment of pneumonia severity: a European perspective. European Respiratory Journal. 2006 Jan 1;27(1):6-8.

7. Macfarlane JT, Boldy D. 2004 update of BTS pneumonia guidelines: what's new?. Thorax. 2004 May 1;59(5):364-6.

8. Shah BA, Singh G, Naik MA, Dhobi GN. Bacteriological and clinical profile of Community acquired pneumonia in hospitalized patients. Lung India. 2010 Apr 1;27(2):54

9. Neill AM, Martin IR, Weir R, Anderson R, Chereshsky A, Epton MJ, et al.Community acquired pneumonia: aetiology and usefulness of severity criteria on admission. Thorax. 1996 Oct 1;51(10):1010-6.

10. Nair, V., Niederman, M. S., Masani, N., \& Fishbane, S. Hyponatremia in community-acquired pneumonia. American journal of nephrology. 2007;27(2): 184-190.

11. Mirsaeidi M, Peyrani P, Aliberti S, Filardo G, Bordon J, Blasi F, et al. Thrombocytopenia and thrombocytosis at time of hospitalization predict mortality in patients with community-acquired pneumonia. Chest Journal. 2010 Feb 1;137(2):416-20.

12. Prina E, Ferrer M, Ranzani OT, Polverino E, Cillóniz C, Moreno E, et al. Thrombocytosis is a marker of poor outcome in community-acquired pneumonia. Chest Journal. 2013 Mar 1;143(3):767-75. 